\begin{tabular}{|l|llll|}
\hline & Journal : Small 10838 & Dispatch : $\mathbf{5 - 1 - 2 0 1 8}$ & Pages : 17 \\
& Article No. : 9391 & $\square$ LE & $\square$ TYPESET \\
& MS Code : JGPS-D-16-00074 & $\downarrow \mathrm{CP}$ & $\boldsymbol{V}$ DISK \\
\hline
\end{tabular}

\title{
3 Theory-Containment in Controversies: Neurath 4 and Müller on Newton, Goethe, and Underdetermination
}

\author{
5 Gábor Á. Zemplén ${ }^{1,2}$ (D)
}

6 A2

$\begin{aligned} 8 & \text { Abstract O } \\ 9 & \text { (prismatic } \\ 10 & \text { assumes the } \\ 11 & \text { darkness is } \\ 12 & \text { retical struc } \\ 13 & \text { century chall } \\ 14 & \text { Newton's o } \\ 15 & \text { provides em } \\ 16 & \text { equivalent, } \\ 17 & \text { rebut the op } \\ 18 & \text { is investiga } \\ 19 & \text { experimenta } \\ 20 & \text { 'limited do } \\ 21 & \text { Goethe's meth } \\ 22 & \text { utilises pola } \\ 23 & \text { controversie } \\ 24 & \text { discusses in } \\ 25 & \text { developed Dut } \\ 26 & \text { pessimistic } \\ 27 & \text { history of the }\end{aligned}$ of experiment

Abstract Olaf Müller's book (More Light) develops a new case for underdetermination (prismatic equivalence), and, as he is focusing on theories of a 'limited domain', this assumes the containability of the theories. First, the paper argues that Müller's theory of darkness is fundamentally Newtonian, but for Newton's optical theory the type of theoretical structure Müller adopts is problematic. Second, the paper discusses seventeenthtury challenges to Newton (by Huygens and Lucas), changes in the proof-structure of Newton's optical theory, and how these affect Müller's reconstruction. Müller's book provides empirically equivalent theories, yet the historical theories were not empirically equivalent, and the same experiments were used to extract different bodies of evidence to rebut the opponent. Third, Goethe's multi-layered critique of Newton's experimental proof is investigated, including his developmental account of prismatic colours, the role of experimental series in rejecting Newton's observations, and his incorporation of the 'limited domain' of prismatic colours in a broader framework. Two key elements of Goethe's method, polarity and strengthening are discussed in contrast to Müller, who only utilises polarity in his account. Finally Neurath's attempts to come to grips with the optical controversies and the prism-experiments with 'blurred edges' are recalled. Müller also discusses in detail some of these experiments and heavily draws on Quine. Neurath developed Duhem's and Poincaré's conventionalist insights and had good reasons to be pessimistic about theory-containment. Their differences provide some additions to the history of the Duhem-Quine thesis.

Keywords Newton - Goethe $\cdot$ Optics $\cdot$ Rational reconstruction $\cdot$ Methodology $\cdot$ Philosophy

\footnotetext{
A3 1 Department of Philosophy and History of Science, Budapest University of Technology and A4 Economics (BME), Budapest, Hungary

A5 2 Institute of Business Economics, Eötvös Loránd University, Budapest, Hungary
} 


\begin{tabular}{|l|llll|}
\hline & Journal : Small 10838 & Dispatch : $\mathbf{5 - 1 - 2 0 1 8}$ & Pages : 17 \\
& Article No. : 9391 & $\square$ LE & $\square$ TYPESET \\
\hline
\end{tabular}

G. Á. Zemplén

\section{3}

34

35

36

37

38

39

40

41

42

43

44

45

46

47

48

49

50

51

52

53

54

55

56

57

58

59

60

61

62

63

64

65

66

67

68

69

\section{Introduction}

Olaf Müller's voluminous inverted spectrum thought experiment utilises aspects of both Newton's and Goethe's views, connecting problems of underdetermination and theoryappraisal with detailed studies of historical theories (Müller 2015). In Newton's first scientific paper traditional spectra were used to argue for the existence of heterogeneous rays in white light. Müller uses inverted, unorthodox spectra-first discussed in detail in Goethe's Beiträge zur Optik - to argue for the possibility of constructing a theory operating with heterogeneous rays of darkness. The mapping of the spectra in complementary settings develops the argument from visual demonstration, some real experiments. And helps Müller to argue for a new case of underdetermination, prismatic equivalence, and to construct a theory of the heterogeneity of darkness (Müller 2016)

To pursue a critical dialogue with the book, the paper explicates philosophical stakes and some facets of the reconstructed controversy. One stake is the aptness of Müller's approach to underdetermination by studying theories of a 'limited domain', another is the plausibility of Müller's view of theories that instructs his reconstructive methodology. Both stakes concern containment, starting with the first: can one, as Müller suggests, clearly delimit the domain in an attempt to provide a strong reading, and restrict the enterprise to a "smaller theory (Optics)" (p. 349)? Müller's book reads at times as if 'optics' pertained to prism-experiments, the scope of the early publications of the protagonists, Newton's New Theory (Newton 1671-72) and Goethe's Beiträge zur Optik (LA I:3), yet it promises the reader a strong reconstruction of the position. The gifted Newton worked over 30 years to republish his theory, comparable to the time Goethe devoted to the subject from the first Beiträge to the Farbenlehre, and his work with entoptic colours.

In their development their theories incorporated and subordinated other domains (e.g. Newton's nomograph of the coloured rings discovered by Hooke, or Goethe's polarity scheme extended to the Archetypal Phenomenon), and these developments were informed by the broader research agendas of the protagonists with the aim of strengthening their theoretical positions. Leaving much of Newton's Opticks and Goethe's Farbenlehre out of the reconstruction assumes that the extensive nature of the research agendas have no bearing on how strongly the positions concerning the earlier, 'limited domain' are supported.

The other containment issue is whether Müller's framework can handle the complexity of these theories. In times when it is much debated what kind of objects theories should be (Halvorson 2012), Müller promises to shed more light on some of the long-debated topics surrounding both Newton's - at first highly — controversial optical theory, and the polarised reception of one of Goethe's top scientific achievements, his Farbenlehre. The book's subtitle ("Goethe mit Newton im Streit um die Farben") alludes to the polarization of views concerning light and colour, and Müller exploits many strands of the rich historiography on his Quinean quest, but can the assumed two-language game, where on the one hand we have sense data (phenomena) and on the other theoretical acts (propositions) contain enough of the controversy, to vindicate Müller's claim, that the book contributes to the philosophy of colour-experimentation (\$I.3.12, p. 81)?

The aim of my appraisal is to scrutinise Müller's reconstructive tools utilised to develop a philosophical argument using a case study. Through my chronologically structured comments I shall focus on specific challenges to and interpretations of Newton's theory from different centuries, revolving around common themes: (1) scope of the proof for Newton's theory, (2) scope of the critiques for Newton's theory. 


\begin{tabular}{|l|llll|}
\hline & Journal : Small 10838 & Dispatch : $\mathbf{5 - 1 - 2 0 1 8}$ & Pages : 17 \\
& Article No. : 9391 & $\square$ LE & $\square$ TYPESET \\
& MS Code : JGPS-D-16-00074 & $\downarrow$ CP & $\checkmark$ DISK \\
\hline
\end{tabular}

Theory-Containment in Controversies: Neurath and Müller on...

Section 2 discusses two points raised by contemporary critics. The first is by Huygens, addressing the problem of extending Newton's demonstration using the Sun's rays to white light, and how this affects Müller's reconstruction. The second is by Lucas, describing subjective prismatic experiments, probably the forerunner to some of the most sophisticated contemporary inverted spectrum experiments, employing reflective aperture diaphragms. Via analysing experimental descriptions of Newton, Lucas, and later of Goethe and Young I shall outline some of the sense-data stakes in the controversy and show that the theoretical alternatives to Newton (utilising different explanatory frameworks) interpreted the data differently. Data-handling issues suggest that the controversy was not settled on the empirical level.

Section 3 is devoted to specific aspects of Goethe's colour-theory, and investigates the picture provided by Müller on Goethe's methodology. To fit his view on theories (inherited mostly from Quine) Müller highlights polarities but downplays the fundamentally developmental perspective that connects Goethe's research on plants, colours, and science. As opposed to Newton's refraction of a beam of light and no interaction Goethe not only discusses refractions at the two edges of a form but also studies the interaction. I shall discuss his critique of Newton's observations in early sections of the Opticks, as well as his experimental series and his study of birefringence.

Newton's optical theory became textbook knowledge hundreds of years ago, yet we still have no uncontroversial account of what exactly the theory was, or how it was proved. How one should do rational reconstruction of the theory utilising Goethe's critique and insight is not a trivial question. Newton's optical theory and the evidential base cannot be easily reduced to equations, formulas, or propositions.

Neurath might have been the first to recognise this, so Sect. 4 is devoted to him. As the birth and development of HPS as a discipline were closely tied to the historiography of Newton's methodology, to appreciate Müller's project it is instructive to recall Neurath's attempts to come to grips with the optical controversies. On the one hand, the two are remarkably similar, connecting the Newton-Goethe controversy with the problem of underdetermination. Both put significant weight on some of the same prism-experiments with 'blurred edges', to be discussed below in detail. As Müller builds on Quine, Neurath develops Duhem's and Poincaré's conventionalist insights. On the other hand, Müller seems sanguine that his project is doable, and, in fact, he has actually done it. Neurath, however, tried to provide a more refined mapping of the group of optical theories, but while he worked on the project, he came up within a year with various, partly overlapping but partly contradictory categorisations (Neurath 1914/5, 1915). ${ }^{1}$ He saw enough of the controversy to be pessimistic about containment:

We see that the mere enumeration of elementary notions is not yet sufficient to place a system of hypotheses historically. One should also always indicate which facts have been neglected, which favoured. The systems of hypotheses of physics, like all other systems of hypotheses, are an instruction directing not only the connectedness, but also the selection of facts. Each system of hypotheses, even if its formulations are of the utmost precision, has, to use this expression, a blurred margin. This always and necessarily exists. The amount of difficulties can grow through new insight; at best we can approach clarity asymptotically. A complete mastery of the whole multiplicity seems an impossibility to us. (Neurath 1983: 23-24).

1 This research partly overlapped with his work on 'the auxiliary motive' and 'pseudorationalism', see also the last section of (Biddle 2013). 


\begin{tabular}{|l|lll|}
\hline & Journal : Small 10838 & Dispatch : 5-1-2018 & Pages : 17 \\
Article No. : 9391 & $\square$ LE & $\square$ TYPESET \\
MS Code : JGPS-D-16-00074 & $\vee$ CP & $\checkmark$ DISK \\
\hline
\end{tabular}

G. Á. Zemplén

\section{Seventeenth-Century Alternatives to Newton: Huygens and Lucas}

Müller's book provides empirically equivalent theories with the kind of deductive proof that characterizes most philosophical debates on underdetermination, but the historical theories were not empirically equivalent, and although both were reasonably well confirmed, they differed on the inductive methods for determining beliefs. Far from being a good example for alternative theories making the identical empirical predictions, the same experiments were used to extract different bodies of evidence to rebut the alternative on the empirical level. Neurath used the example a century ago to illustrate that both 'theory' and 'data' are fallible.

In his carefully crafted if somewhat overdramatised account of the controversy-conglomerate, Müller assumes that Newton's (or Goethe's) theory is a more or less easily delineable entity. From his perspective the time was not ripe for Newton's theory when it was first published (p. 387), disregarding the possibility that the theory was not ripe at that time, and that the evidence-base or the presentational devices needed improvement. Below I shall outline only two of the many early critical objections that Newton received, and show how the glitches noted over 300 years ago by Huygens and Lucas affect the provability of Müller's alternative theory. I believe that both criticisms contributed to a stronger formulation of the evidential base of Newton's theory, they changed the way he presented the theory, and also changed the structure of the proof of the theory, influencing what the 'limited domain' is, and how it could be proved as being embedded in a more complex theory.

\subsection{Two Types of Sources of White Light: Huygens}

Oldenburg sent a copy of the "New Theory" to Christiaan Huygens, accompanied by a note that drew attention to Newton's work. About the theory of colours Huygens's first reaction ("elle me paroit fort ingenieuse") was positive (Turnbull 1959: 135). In the following letter his opinion was again favourable, but with some reservations. And in his third letter (27 September) he picked up a line of argument from Hooke, ${ }^{2}$ and discussed a surprising idea confirmed in the nineteenth century by Helmholtz: white might be composed of only yellow and blue, that is, mixing spectral yellow and blue can result in white (with theatrical lighting and filters we get 'light gray', see Holtsmark 2012: 17). Newton in his reply was not amicable (3 April, 1673):

If therefore M Huygens would conclude any thing, he must show how white may be produced out of two uncompounded colours; $\mathrm{w}^{\mathrm{ch}}$ when he hath done, I will further tell him, why he can conclude nothing from that (Turnbull 1959: 265).

From Newton's perspective the white composed of yellow and blue would have different physical properties, would not be the same white as the sun's white, cold not "be truly called white" (Turnbull 1959: 265). Huygens retorted:

\footnotetext{
${ }^{2}$ Both Hooke and Huygens used two colours (explananda) to account for colours, as opposed to Newton's indefinite number of colours. These modificationist accounts belonged to the class of theories that Newton rejected in his New Theory, the basic colours were different, but the two-colour hypothesis was supported by parsimony. Huygens pointed out the simplicity of a mechanical model operating with only two colours, and stated that Newton's theory could be a very plausible hypothesis (Turnbull 1959: 235-236).
} 


\begin{tabular}{|l|llll|}
\hline & Journal : Small 10838 & Dispatch : $\mathbf{5 - 1 - 2 0 1 8}$ & Pages : 17 \\
& Article No. : 9391 & $\square$ LE & $\square$ TYPESET \\
& MS Code : JGPS-D-16-00074 & $\downarrow$ CP & $\checkmark$ DISK \\
\hline
\end{tabular}

Theory-Containment in Controversies: Neurath and Müller on...

I desire to know his meaning when he adds that though I should prove that white may be made of only two primitive colours, yet it concludes nothing against him, \& yet he says p. 3083 of the transactions that all the primitive colours are necessary to the composing of white. (Turnbull 1959: 286)

Newton's impatient and slightly arrogant answer on 23 June 1673 ended the correspondence of the two (at the time probably greatest) writers on the topic. Huygens's comment put Newton on defence, some propositions of the New Theory had to be modified (influencing proposition 1., 2., 3., 5., 7., 8). Newton had to (and did) restrict his claims to the white light of the sun, greatly reducing the universal nature of his theory. As Shapiro convincingly argues, this "embarrassing dichotomy" diminished the power of appealing to similarity or analogy, like one of the two (independent) arguments presented in the Lectiones (Shapiro 1980: 225). Huygens pointed out that the proof structure of Newton's theory needs to specify the source, and cannot just go with a phenomenological category 'white'.

Part I of Müller's book dutifully acknowledges this limitation: ending the chain of argumentation, he states: "(R) White Sunlight is a heterogeneous mixture of diversely refrangible light rays." [\$I.5.10., p. 110, also $\left(\mathrm{R}_{\mathrm{EC}}\right)$, §IV.I.5., p. 319]. The argument developed in Part II, however, leaves the source out of the question: "Goethe ... searched for a bipolar Theory in which light and darkness play an equally legitimate causal role. This much searched for middle way he did not find" (p. 144). I shall return to the evaluative remark in the next section, and here only want to note that the question of the source of rays is gradually dropped in Müller's book. By the time we reach the equivalence table of the phenomenological concepts mapping the orthodox and unorthodox crucial experiments, only lightness and darkness and white light and black shadow are charted (p. 203).

The Sun is not a part of Müller's 'orthodox' description of Newton's experiment, a rather unorthodox solution to Huygens' challenge. Müller urges physicists to consider the (counter)intuitive conversion to an inverse corpuscular theory, but his rays of darkness are created ex nihilo in the philosopher's conceptual lab. For the cogency of the proof, Newton was forced to disambiguate the source of white. Could two types of darkness sources (corresponding to Newton's and Huygens's/Helmholtz's white) be meaningfully distinguished before refraction in Müller's theory by specifying two types of conditions?

\subsection{Two Coloured Fringes of Equal Length: Lucas}

The first inverted experiment in Müller's reconstruction comes from the most ardent Jesuit opponent of Newton (\$II.3.16, p. 163). In one of his subjective prismatic experiments, Lucas cut out black and white circles, and placed them on white and black background. Viewing them from 16 feet, he found that "the yellow in the inferior limbus of the black circle fully equalld in length ye violet of the white one, even whilst the spectrum of the white circle was represented at its greatest Length." Also, "the red of the superior limbus

\footnotetext{
${ }^{3}$ There are many subtle shifts in position, opponents cornered Newton after his early exposition of the optical theory. Müller's rays are 'strongly immutable' (they exist before the first refraction), and he assumes a Naturkonstant. Newton's argument in extending the reasoning from the second prism to the first in the crucial experiment also employs a principle of economy - a notion used in optics at least since the Catoptrics of Hero of Alexandria (Cohen and Drabkin 1948 (1969)) - but this has been challenged in the controversy, and helped Newton restructure his proof (no experiment is called crucial in the Opticks). Müller notes that he is probably the only one who thinks Newton's theory follows from the crucial experiment (§I.5.17, 117).
} 


\begin{tabular}{|l|llll|}
\hline & Journal : Small 10838 & Dispatch : $\mathbf{5 - 1 - 2 0 1 8}$ & Pages : 17 \\
& Article No. : 9391 & $\square$ LE & $\square$ TYPESET \\
\hline
\end{tabular}

G. Á. Zemplén

202

203

204

205

206

207

208

209

210

211

212

213

214

215

216

217

218

219

220

221

222

223

224

225

226

227

228

229

230

231

232

233

234

235

236

237

238

239

4FL01

4FL02

4FL03

$4 \mathrm{FLO} 4$

4FL05

4FL06

4FL07

5 FL01

$5 \mathrm{FLO} 2$

$5 \mathrm{FLO3}$

5 FL04

of ye white circle equalled in length the violet, or rather blew of the black one". This demonstrates that "very different colours, yea quite opposit ones may at the same incidence appeare under the selfe same degree of refraction" (Turnbull 1960: 106-107).

If Newton dismisses this critique (as, for the first case the colour yellow does not originate in the black region or the boundary, but from light around the circle) could Müller not dismiss the critique? Well-acquainted with scholastic concepts and modificationist colour theories (Descartes, Hooke, Huygens, Lucas), Newton took the objection seriously. The description hinted at an alternative to Newton's theoretical understanding of refraction. ${ }^{4}$ Contrary to Newton's New Theory, the later published Opticks started the investigation with subjective experiments and image displacement (Book I Part I Prop. 1. Exp. $1-2)$, and not with light from the Sun. Very specific colours were used to rebut the alternative, to be discussed in the next section.

Many readers appreciate the complexity of the move from a venerable mixed mathematical science, an atemporal world of geometrical mapping relations, to modern optics as a part of physics, where for centuries ontological stakes were high (is light a particle, a wave, or both, or none), with significant impact on the emerging popular understanding of science.

Modificationist theories, when dealing with the problem of the elongation of the spectrum could separate the chromatic problem and the geometric problem, and both Lucas and Goethe discussed refraction without the appearance of colour (Turnbull 1960: 250; Goethe 1988, Farbenlehre Didaktischer Teil (FL-DT) \$195-196). Newton, in contrast, proposed a solution where the law of sines, a major disçovery of the seventeenth century could be saved in a modified form by connecting the geometric and the chromatic problem.

Müller is nonchalant regarding modification-theories (p. 87), and minimises the burden of proof in both the reconstruction (the Optical Lectures is too complex to present, §I.2.14, p. 64), and in the explication (on his thought experiment on unordinary spectra (pp. 289-290). Lucas's critique shows how a modificationist framework can be used to exploit the circular features of Newton's theory, and has some similarities with Goethe's treatment of black and white on a par. Both draw attention to the equal extension of (pairs of) coloured fringes of the displaced image..$^{5}$ At stake is whether we think of the camera obscura as a tool in which the outside world, including the Sun is mapped, or a setup, where rays suffer refraction to yield a spectrum. The early part of the imagery of the Opticks conformed to the tradition, but later plates introduced parallel bundles, sometimes even inside a camera obscura (Zemplén 2017a), at odds with the tradition of mapping angular sizes.

Newton's ray-concept was intricately tied to a corpuscular assumption, and so is Müller's alternative theory to Newton's. As Torger Holtsmark noted, with his definition of ray Newton "took an important step away from the old established geometrical image

\footnotetext{
${ }^{4}$ Before Newton, the coloured fringes were connected to the "ancient theory of the nature of the rainbow's colors, a theory which held that a succession of modifications of sunlight by the droplets of a rain cloud produced the colors of the bow". In mechanical hypotheses, it was generally "a minor perturbation restricted primarily to the edges of the homogeneous beam of sunlight". The mixture of light and shade "at the region of contact between the refracted beam and the dark" is a result of "varying 'condensation' and 'rarefaction' produced at the edges of the beam", or it might emerge "by some other mechanical modification" (Kuhn 1958: 30-31).

${ }^{5}$ Goethe describes the ways in which light interacts with darkness, white with black to show that "without a boundary $[\ldots]$ no colors appear. That is, the boundary condition is fundamental" (Sepper 1988, p. 222). As Jonathan Westphal notes, "the crucial claim made by Goethe, which is at the centre of his polemic against Newton, [is] that (as we would say) colour is an edge-phenomenon" (Westphal 1987: 9).
} 


\begin{tabular}{|l|llll|}
\hline & Journal : Small 10838 & Dispatch : $\mathbf{5 - 1 - 2 0 1 8}$ & Pages : 17 \\
& Article No. : 9391 & $\square$ LE & $\square$ TYPESET \\
& MS Code : JGPS-D-16-00074 & $\downarrow$ CP & $\checkmark$ DISK \\
\hline
\end{tabular}

Theory-Containment in Controversies: Neurath and Müller on...

optics into physical optics. At the same time he introduced the above mentioned terminological confusion, namely by applying the operational rules of the old image optics upon a reinterpreted ray concept" (Holtsmark 2012: 39). Can darkness-rays be refracted without colour in Müller's theory? As Müller is definitely putting more weight on Newton's shoulder than Goethe, to me a naturally occurring query is whether he thinks that two meaningful inverted theories are also constructible based on the (atemporal) image-mapping tradition, the contemporary alternative to Newton.

Interestingly, Newton's theory developed in stages, and some early drafts contained what Müller takes to be partly Goethe's and partly his novel, post-Newtonian and critical insight. In the Optica, Part II, Lecture 1 Newton still uses a broad modificationist framework, as opposed to his rejection of the whole tradition in the New Theory:

I find that the modification of light whereby colours originate is connate to light and arises neither from reflection nor from refraction, nor from the qualities or any modes whatsoever of bodies, and it cannot be destroyed or changed in any way by them. (Newton 1984, pp. 436-437)

Of course 'connate' modification is not much of a modificationist theory, but in this manuscript of the Optical Lectures, Newton still did not distance himself from treating white and black on a par, as he states: "I find that the colours white and black, together with intermediate ashens or grays, are made by rays of every sort, confusedly mixed" (pp. 436-437). In the New Theory this is only stated for white (Prop. 7., challenged by Huygens).

\section{Goethe's Theory-Building Practice}

It seems that at times Goethe deliberately avoided the terminology of Newtonian optics, in later writings the use of the word "Bild" (not uncommon among his contemporaries) as opposed to "rays of light" makes his Farbenlehre (FL) rather difficult to translate (Burwick 1989). The first proposition of Newton's Opticks stated: "Lights which differ in Colour, differ also in Degrees of Refrangibility", and Goethe took much care to note in the polemical part (PT) that if different terminology is used, then the same phenomena could be used to support other propositions, like: "images which differ in colour appear to be displaced by refraction in various ways" (FL-PT \$29). Newton's description is unnecessarily theory laden, granting some form of heterogeneity of some supposed entities. ${ }^{6}$

Given the title of Müller's book (More Light), I was surprised to see how little of Goethe's insight was utilised in the approach picked by the author. Goethe's method is unlike some hallmark eighteenth-century theories like Linné's, an early and pervasive influence on Goethe, or Newton's theory, later so vehemently criticised by him. Newton used the Sun's spectrum to argue for 'sorts of Rays', and Linné's classification labelled similarities (definitio, genus) and differences (differentia, species). Both looked for

\footnotetext{
${ }^{6}$ This is what Müller at points attributes to Goethe, over-exploiting the source, and equivocating his nonmodificationist alternative to Newton with Goethe's views. In Müller's early treatment Goethe would have rejected rays of darkness, his criticism of the "ray-concept" is discussed (§II.3.5 p. 152), after accrediting Goethe with thinking of the lack of light (Abwesenheit) as causal counter-idea ( $\$ I I .3 .3$ p. 150), by the end of the book Goethe is accredited and praised for formulating the heterogeneity of darkness ("der von ihm formulierten Heterogenität des Finsternis” §4.7.7., p. 419). In his recent article Goethe's dissolving, splitting, and scattering "black image" is praised as the idea that "darkness and blackness are composite phenomena" (LA I.7, 86, Müller 2016).
} 


\begin{tabular}{|l|lll|}
\hline & Journal : Small 10838 & Dispatch : $\mathbf{5 - 1 - 2 0 1 8}$ & Pages : 17 \\
& Article No. : 9391 & $\square$ LE & $\square$ TYPESET \\
MS Code : JGPS-D-16-00074 & $\nabla$ CP & $\checkmark$ DISK \\
\hline
\end{tabular}

G. Á. Zemplén

discriminating traits (measurably different refrangibilities and differently coloured regions of the spectrum; observable and countable natural referents like the number of pistils) and gave intensional definitions of species (of light rays and of living forms).

The focal issue for Goethe was development, not classification or ascribing properties to unobservables. His alternative (transformational) method did not rely fundamentally on the species concept. The systematic studies of several domains might appear ascientific at first glance, as they are minimising nomenclature, counting, and abstract entities, and are capturing series via exposing links, directions and tensions.

To rediscover Goethe as a highly influential scientific thinker is not unusual for the history of Goethe-reception in physics, and many have suspected mathematics behind his approach. Heisenberg recognised a similarity between modern theories of symmetry and number on the one hand, and Goethe's elaboration of the morphology of colour phenomena ${ }^{7}$ on the other. Several commentators agree that there are interestingly 'formal' aspects of Goethe's science. Here we probably share the same ground with Müller. I think one can go as far as Hegge in stating that

His aim is to arrive at a comparatively small number of simple, well-defined elements, corresponding to the axioms of geometry, that is, expressions which are not further reducible to others, but express basic concepts in the system from which the other elements are derived. (Hegge 1987: 202)

As has been noted by Goethe, his 'superlative' understanding of theory-construction is based on two concepts, polarity and enhancement/progression (Steigerung). ${ }^{8}$ Müller exploits the polarity-aspect, but brackets the enhancement-aspect, not appreciating one of the most fundamental characteristics of Goethe's approach. I shall therefore offer an abbreviated reconstruction of Goethe's alternative to model-building, utilising not just as Müller does polarities, one of the cornerstones of his nature studies, but also investigating the enhancement-advancement aspect ("Steigerung") in his multi-layer critique of the evidence base of Newton's theory. First I shall address his developmental account of prismatic colours (3.1) followed by a short discussion of his experimental series (3.2), and his study of birefringence (3.3).

\subsection{A Developmental Account of Colours}

Goethe pursued the inner dynamics of the domains under investigation. A new domain generally linked the domain to polarities already in use. Most explanatory terms create geometrical or intermodal spaces. In his early work on plants "expansion-contraction", which "would have to be manipulated as expertly as algebraic formulae, and would have to be applied in the right places" (Müller 1989: 72, §102). In later botanical texts 'vertical'

\footnotetext{
7 Dennis Sepper adds that "One intriguing aspect of Goethe's exposition of the phenomena is that it incorporates a fundamental concept of modern mathematics and mathematical physics, the limit of a series, potentially if not actually infinite. The superexperiment, whether continuously or discretely varied, allows one to approach phenomenally a limit that may not be reachable in fact - for instance, an aperture with the breadth of a mathematical point" (Sepper 1988, p. 75). Sepper also cites a manuscript, where Goethe derives straight-line boundaries from a curved boundary by performing what amounts to a continuous topological deformation of space to transform a circle to a line by changing viewing angles in subjective prismatic experiments (ibid. p. 76), and Ribe draws an analogy between Goethe's modificationist model and differential equations (Ribe 1985, p. 330).

8 As the late Goethe criticises his own earlier work: "The composition lacks the consummating concept of two of Nature's activating forces: polarity and progression” (Müller 1989, p. 245).
} 


\begin{tabular}{|l|llll|}
\hline & Journal : Small 10838 & Dispatch : $\mathbf{5 - 1 - 2 0 1 8}$ & Pages : 17 \\
& Article No. : 9391 & $\square$ LE & $\square$ TYPESET \\
& MS Code : JGPS-D-16-00074 & $\downarrow$ CP & $\checkmark$ DISK \\
\hline
\end{tabular}

Theory-Containment in Controversies: Neurath and Müller on...

and 'spiral' tendencies. And in the Beiträge symmetrical coloured fringes, containing thicker red and blue and thinner yellow and violet bands. The explanatory schemes have shared features not just in plant morphology, but also regarding prismatic colours. Theories of different domains display structural family-resemblance.

Goethe's historically significant scientific achievements utilise polarity, but not only polarity. In my view, a noteworthy feature of Goethe's method is that where it was applied with some success (comparative osteology, plant morphology, colour-studies), it always utilised some pattern or progression (formation, transformation) in a phenomenal domain to help differentiate conformity from deviation. ${ }^{9}$ Once an advancing series is located or some ordering is achieved, one can develop a framework using polarities as explanatory crutches, as reference points to help locate regularities as well as irregular forms. Goethe used his observational and experimental series as a research tool in his exploratory research (Ribe and Steinle 2002), and to establish the polarity and progression of the phenomenal domain. It was also used in the rejection of the Newtonian experimental proof.

Let us first investigate the sense-data stakes of Goethe's critique, and his description of some subjective experiments, where polarity is apparent between warm and cool colours, the two pairs of thinner and thicker coloured bands (the polarity aspect of the explanatory structure). As we move away from the prism, make the strip thinner, or use a prism with greater refractive angle, the coloured bands spread out. Goethe discusses the two refractions (at the edges of a form) and the interaction as opposed to Newton's refraction of a beam of light and no interaction. When the fringes meet, new colours appear, and the enhancement aspect is just as crucial to Goethe's account as is polarity. Enhancement in bandwidth results in the overlapping of the two coloured bands, and a new polarity of complementary colours emerges: green (visible in Newton's spectrum) opposed to the extra-spectral red (peach blossom/magenta) absent from Newton's colour wheel.

A telling pictorial sign of the advancing, developmental features is that in Goethe's drawing of spectral colours, the interaction of edge-colours is a focal property of the images (Coloured Tables 8-9 in Müller's book). The new colours spread further, and extinguish the two colours that gave birth to them: the yellow and the blue in the case of the white strip, the violet and the red in the case of the black strip. Bracketing the enhancement/advancement aspect is a lopsided interpretation of Goethe, who was an 'extreme partisan' of the evolutionary idea, as Darwin referred to him. Goethe gave a detailed description of what is also called the Bezold-Brücke hue shift: at lower light intensities we see more red and green, at higher light intensities the blues and yellows dominate (Duck 1987). The colour-refrangibility correspondence wanes as matching a unique hue with a binary hue is light-intensity dependent. As Michael Duck writes:

It is true that he [Goethe] displayed a certain obsessiveness about his theory of colour, but that was, I contend, largely due to the sheer coincidence that the BezoldBrücke phenomenon affects the appearance of the subjective spectrum in exactly the way that his totally unrelated theory predicts. It was this extraordinarily fortuitous fact that lead him to put a false interpretation upon what he saw. Since the phenomenon was not consciously identified long after his death, he could hardly be

\footnotetext{
${ }^{9}$ Goethe's observational method delimited the applicability of the toolset to specific domains. In botany, for example, he gave up on giving an account of the subterranean parts of plants. If no advancement can be traced, then his comparative method is not applicable. Given the scope of his method, this was an unjust demand ("Unbillige Forderung"): "it is advance solely that could attract me, hold me, and sweep me along my course" (Müller 1989: 118).
} 


\begin{tabular}{|l|llll|}
\hline & Journal : Small 10838 & Dispatch : $\mathbf{5 - 1 - 2 0 1 8}$ & Pages : 17 \\
& Article No. : 9391 & $\square$ LE & $\square$ TYPESET \\
\hline
\end{tabular}

G. Á. Zemplén

blamed for thinking that what he saw through the prism bore out and confirmed his theory (Duck 1987, p. 795).

There is a reduction of the spectra, not accounted for in Newton's theory, and Müller similarly leaves hue-shifts unaccounted for. Müller's theorising about colours could be called Antediluvian in many aspects ${ }^{10}$ and his model does not link to the colours we see when we look at the experiment, only to abstract properties. His mapping game is static (5-5 colours, CT 10-13) and uses Newton's diagrammatic convention, as his rays of darkness do not interact (CT 16-27), though a few snapshots acknowledge the effect (CT 30), without informing his theory. This approach neglects some of Goethe's crucial observations, presaging physiological insights into colour-vision, and is downplaying what Goethe saw as well as how he explained what he saw.

I am less interested in the dynamics of hue-shifts and related phenomena than in how Goethe' enterprise provided a multi-layer critique of Newton's theory. In the controversy, the evidential base is not unaffected by the theoretical content, as experimental descriptions are directed by the theoretical outlook. Müller notes the peculiar red/blue terminology of the Opticks (§I.4.3, p. 93), but does not discuss the way colour-terminology is utilised in the debate in detail. In the following I shall pick this as the red thread to show some of the challenges to contain optical theories. A disagreement concerning the empirical details, the description and interpretation of observations in the phenomenal domain Müller picked (optics), quickly leads us to a methodological debate on picking protocols. The rival theories differ on how they select and reconstitute facts, and in Sect. 4 these insight will be used as an argument against the assumed containability of the optical theories in qestion.

\subsection{Rejecting Empirical Proof with Experimental Series}

In Newton's experiment, possibly to rebut the type of challenge Lucas raised, a rectangular piece of paper painted half blue, half red is viewed through a prism. Why would Newton use blue instead of violet if the extremities of the spectrum are red and violet? There are telling signs that Newton carefully picked certain 'basic' colours, and that colour-terms played a role in how strong the empirical support for the theory (and Newton's rayconcept) was. ${ }^{11}$ Lucas writes about "scarlet" and "violet" colours (Turnbull 1960: 9). In his reply Newton writes of "blew" and "red" (Turnbull 1960: 259).

In Goethe's reconstruction and critique in the Polemical part of the Farbenlehre (FLPT), choosing the colours blue and red is deceiving. ${ }^{12}$ Goethe refers to the explanation of the coloured fringes (FL-PT §43, FL-DT §§258-284) before concluding that the

\footnotetext{
${ }^{10}$ As an account of objective colours, it equates colour with a property of a theoretical entity outside the observer. A recent attempt developed Locke's inverted spectrum thought experiment to discuss relations among consciousness, brain, behaviour, and scientific explanation, exploring isomorphism constraints in subjective colour-perception (Palmer 1998).

${ }^{11}$ In the Opticks I/2, Exp. 5. Newton writes about the separated ('pure') spectral colours being further refracted: "For by this Refraction the Colour of the Light was never changed in the least. If any Part of the red Light was refracted it remained totally of the same red Colour as before...The like Constancy and Immutability I found also in the blue, green, and other Colours" (Newton 1952: 122-123). Yellow is suspiciously not listed, as here further fringes are visible.

12 Goethe aims to show that the 'experimental' proof that Newton uses has superfluous parts (FL-PT \$35-39), concluding that the description is endowing Newton's experiments with purity (FL-PT §41). To talk of -ibilities and -ities ("Ibilitäten,... Keiten" FL-PT §29) is far-fetched, unsupported, the proposition is not established, but only supported by the experiments. At points Goethe interferes even more with the process of idealisation, claiming that it is invalid.
} 


\begin{tabular}{|l|llll|}
\hline & Journal : Small 10838 & Dispatch : $\mathbf{5 - 1 - 2 0 1 8}$ & Pages : 17 \\
& Article No. : 9391 & $\square$ LE & $\square$ TYPESET \\
& MS Code : JGPS-D-16-00074 & $\downarrow$ CP & $\checkmark$ DISK \\
\hline
\end{tabular}

Theory-Containment in Controversies: Neurath and Müller on...

387

388

389

390

391

392

393

394

395

396

397

398

399

400

401

402

403

404

405

406

407

408

409

410

411

412

413

414

415

416

417

418

419

420

421

422

423

424

425

426

427

428

429

430

431

432

433

displacement is an illusion (FL-PT §45). He draws attention to the accompanying illustration, where the edges of the displaced image are fuzzy. An obviously elliptic description of the observations is used as proof, and the explanation about the composite nature of the colours is offered by Newton only much later in the text.

In Goethe's experimental series, a rectilinear outline is a better representation of the observations with most colours, recalling Lucas's critique to mind. It could be debated in the blue/red case, but from carrying out many investigations, it simply shows that the illusion of two displaced rectangles is a powerful one. What is seen is just the two coloured stripes and the usual blue-violet and red-yellow edge phenomena. In the first case the mostly red edge is added to the red stripe on one end, in the second the mostly blue edge is added to the blue stripe on the other end - creating an illusion of displacement.

The reception of Goethe's Farbenlehre shows how the different ways of seeing lived side-by-side, how the two mathematical idealizations, one using an encompassing rectangle, the other two, displaced rectangles were both empirically confirmed. About the same experiment, criticising Goethe's treatment of Newton, Thomas Young writes:

He gives us, for instance, in his third plate, a number of coloured objects to be viewed through the prism: one of the objects is a space, of which one half is coloured red, and the other blue; and in the representation of the prismatic appearance, the two halves are still placed side by side, and terminated by the same rectilinear outline. This is an 'experimentum crucis': we have looked through the prism, at the identical figure of the third plate, and it does not appear as Mr. von Goethe has represented it in the fourth; but the blue image is manifestly more displaced by the effect of refraction, than the red (Young 1814), see also LA II 5A 91-92.

Young is keen to pick a 'crucial experiment', but Goethe's argument includes not only a critique of the experimental description, but also a critique of the methodology, the very concept of crucial experiments:

I venture to assert that one experiment, even several experiments combined, prove nothing; indeed, that nothing can be more dangerous than the attempt to confirm a theory by experiments; and that the greatest errors have arisen precisely because its dangers and its inadequacies were not realized (HA 13:15).

Goethe's polemic (FL-PT §§35-46, also referring to FL-DT §§ 258-284) operates with the notion of the typical, and passes judgment on a single experiment by referring to a series of experiments, a systematic exploration of a set of phenomena. If image displacements $\left(\mathrm{P}_{1}-\right.$ $P_{n}$ ) show regularities $\left(R_{1}-R_{n}\right)$, then it is justified to use diagrammatic convention $(C)_{G}$. Newton's example $\left(\mathrm{P}_{\mathrm{a}}\right)$ is an atypical phenomenon overtly not representing some regularity $\left(\mathrm{R}_{\mathrm{a}}\right)$, and is used by Newton to justify diagrammatic convention $(\mathrm{C})_{\mathrm{N}}$. Newton, when using dark red and blue, is deliberately choosing $\mathrm{P}_{\mathrm{a}}$, and screening thus $\mathrm{R}_{\mathrm{a}}$ (the blue and red fringes), and so Newton's practice of idealisation is illegitimate, yet he portrays the results of illegitimate idealisation as facts. The legitimate basis of idealisation can be typical phenomena only, and $\mathrm{P}_{\mathrm{a}}$ cannot be the basis of idealisation, because it is atypical. As a systematic variation of conditions sufficiently explains why $R_{a}$ is not overtly manifest in $\mathrm{P}_{\mathrm{a}}, \mathrm{P}_{\mathrm{a}}$ is a secondary phenomenon, and $(\mathrm{C})_{\mathrm{N}}$ is a less apt diagrammatisation.

Restricting the enterprise to 'smaller' optical theories suggests that Müller aims to investigate a 'limited domain' (p. 349) but the empirical descriptions are intertwined with broader research methodologies and the epistemic values. Müller's book-length philosophical exercise assumes a two-language game: on the one hand we have sense data (phenomena) and on the other theoretical acts (propositions). A discussion on the language 


\begin{tabular}{|l|lll|}
\hline & Journal : Small 10838 & Dispatch : $\mathbf{5 - 1 - 2 0 1 8}$ & Pages : 17 \\
Article No. : 9391 & $\square$ LE & $\square$ TYPESET \\
MS Code : JGPS-D-16-00074 & $\checkmark \mathrm{CP}$ & $\nabla$ DISK \\
\hline
\end{tabular}

G. Á. Zemplén

434 of descriptions quickly leads to a methodological disagreement on how to interpret the 435 evidence, the experimental setup, and the proof of Newton's ontological claim. Handling 436 the complexity in a controversy is difficult in a framework with a stable evidence base and 437 provability of 'theoretical acts' ("theoretische Tugenden" p. 363). The theories in question 438 were born in times of conflict. For either of the theories a number of auxiliary assumptions 439 and different reports of observations were used to provide-supposedly strong enough440 support for the position. Müller's decontextualised assumptions about theories are fitted for 441 a textbook account of already justified knowledge-parts, but controversial science is a 442 network of disagreements with usually no stable evidence base. In the examined case, often 443 the inspiring ideas behind the theory-development were very different. Some theories were 444 at times more dominant, but for centuries there was hardly ever 'closure' or 'consensus' in 445 the field.

446 Huygens has already been mentioned, whose study of birefringence was closely con447 nected to his non-Newtonian alternative physical optical theory (Dijksterhuis 2004). As Müller is not mentioning polarisation among the formal properties of light-points and trajectories below I shall discuss the role the anomalous image-producing properties of Icelandic spar played for Goethe. The increasing interest on Huygens's side in Erasmus Bartholin's discovery (Lohne 1977) and Newton's theory stimulated his active interest in developing a theory of light (Shapiro 1973: 240), and Goethe used the singular observations of the atypical phenomenon to link two classes of colours in his Farbenlehre, to extend his explanatory scheme to connect two phenomenal domains.

\section{5}

\subsection{Linking Classes of Dioptric Colours via Birefringence}

The Farbenlehre is structured much like a scala naturae, leading from physiological colours (most transient colours), through the increasingly less transient physical colours, to fixed chemical colours. The part on physical colours starts with the chapter on dioptric colours, which appear when light, darkness, and colourless transparent or translucent media interact (FL-DT, §143). The first class of dioptric colours in the didactic part of the Farbenlehre introduces the archetypal phenomenon's basic polarity, light and shadow. [Grund-und Urphänomen] HA 13: 367, FL-DT §174:

On the one hand we see/ight or a bright object, on the other, darkness or a dark object. Between them we place turbidity and through this mediation colours arise from the opposites; these colours too are opposites, although in their reciprocal relationship they lead directly back to a common unity (Goethe 1988, 12: 195; FLDT §175).

The explanatory model developed here is unlike the boundary-modificationist account of Goethe's Beiträge (the second class of dioptric colours), the earlier prismatic games with coloured fringes extensively untilised by Müller. The medium serves for enhancement, giving rise to the yellow (red) sun-akin to Aristotle's medium-modificationism proposed in his Meteorologica - and the blue (at night black) sky.

The anomalous image-producing properties of Icelandic spar first triggered a tentative idea in an unpublished draft from October 1793: "Why should the Medium not be able to bring forth a double image through a cause that is unknown to us" (LA I, 3: 158). The concept was developed in his later Farbenlehre, where Goethe conjectures about the existence of a double image, and a special subcategory, the "auxiliary image" or Nebenbild, used as a link, to connect the archetypal phenomenon (medium-modification) 480 and the edge-phenomena in prismatic experiments (boundary-modification). The two 


\begin{tabular}{|l|llll|}
\hline & Journal : Small 10838 & Dispatch : $\mathbf{5 - 1 - 2 0 1 8}$ & Pages : 17 \\
& Article No. : 9391 & $\square$ LE & $\square$ TYPESET \\
& MS Code : JGPS-D-16-00074 & $\downarrow$ CP & $\checkmark$ DISK \\
\hline
\end{tabular}

Theory-Containment in Controversies: Neurath and Müller on...

481

482

483

484

485

486

487

488

489

490

491

492

493

494

495

496

497

498

499

500

501

502

503

504

505

506

507

508

509

510

511

512

513

514

515

516

517

518

519

520

13FL01

13FL02

13FL03

13FL04

classes of dioptric colour phenomena have a unified explanation with the help of an additional concept, the Nebenbild (Zemplén 2006a).

Observations inspired the auxiliary image (a theoretical term?), and with it Goethe linked the earlier research to the new. Edge-colours are subsumed under the archetypal image and this suggests that the theoretical core-elements are transposable (Amrine 1990), and, as polarity and progression survive transformation, the two key elements have the potential to be used recursively, subordinating the earlier explanatory scheme under the more developed one.

Müller's contribution to the philosophy of experimentation glances over some of the most challenging aspects of Goethe's science here only alluded to. ${ }^{13}$ The method manipulating polarities is a lot like a yin-yang theory (building on opposing yet complementing primitives) tailored to fit specific phenomenal domains. The polarities relate to the empirical domain and inform the linguistic domain, the archetypal phenomenon displays the essence of polarities, and polarities are essential to the linguistic description. The method establishes a peculiar grammar that informs observation and concept-formation that can travel across domains. Polarity and enhancement are relational concepts that facilitate the empirical work (Zemplén 2017b), but in Müller's voluminous inverted spectrum project only one is used for his replacement-game.

\subsection{Neurath's Classification of Optical Theories}

Otto Neurath-possibly inspired by Goethe-reproduced part of the diagram Goethe also criticised, and hinted at the 'blurred edges' of theories (Zemplén 2006b). Neurath looked at these optical theories because they were significant for the emerging scientific world view, and they were hard nuts to crack, with no shortcuts, like "Maxwell's theory is Maxwell's system of equations". During his work, he analysed some theories in detail, most notably Newton's Opticks, both with respect to language use, and the use of diagrams. One of the driving forces for Neurath was the recognition that focus only on the abstract and symbolic properties of theories might be unjustified, and other elements of theory-propagation should also be accounted for:

Some modern physicists, who, like Poincaré or Duhem, are reckoned among conventionalists, allow that the mathematically important features are relevant to classification and analysis. But this leaves open the philosophical question. Those who wish to give more weight to the imagery of hypotheses (as I believe one must in some cases), may without contradiction add this to the analysis (Neurath 1973: 102-103).

As we need theories to classify things, Neurath thought that we need theories to classify theories (Neurath 1983: 31), and he attempted to provide an account of optical theories by their employment of 'elementary notions', like 'periodicity' or 'emission'. This first step of analysis was followed by the search for the driving (often analogical) ideas, and, to extend the conventionalism of Poincaré and Duhem, a critical appreciation of how the theory 'connects' and 'selects' facts.

${ }^{13}$ The method is also reflexive, it enables Goethe to display his own development as a scientist. For Goethe as a historian of science can use it to develop models for social science: the intertwining polarities (authority and experience) are displayed by Roger Bacon, a typical 'scientist' in the irregular Medieval period (atypical for the lack of progress). 


\begin{tabular}{|l|lll|}
\hline & Journal : Small 10838 & Dispatch : $\mathbf{5 - 1 - 2 0 1 8}$ & Pages : 17 \\
Article No. : 9391 & $\square$ LE & $\square$ TYPESET \\
MS Code : JGPS-D-16-00074 & $\checkmark \mathrm{CP}$ & $\checkmark$ DISK \\
\hline
\end{tabular}

G. Á. Zemplén

His normative historical project was a way to develop tools to overcome epistemically detrimental meaning-polarisation: "Dichotomies... are not only crude intellectually, but also mostly the product of scientific pugnacity" (Neurath 1983: 15). Neurath's early work on the classification of systems of hypothesis in optics provided many of the key insights of his later philosophy of science (his boat-metaphor and the Neurath-principle are well known). His approach was pluralistic:

If one sees that the choice of the original analogy is of no decisive significance for the structure of the system of hypotheses, one is involuntarily impelled to accord equal value to different systems of hypotheses to the degree to which they comprise the multiplicity of reality. Thus it easily becomes a task of patience to succeed in modifying a given system of hypotheses until it achieves the same success as another system. Duhem's opinion is that, if a sufficiently high prize is offered, one could get a modified emission theory today that would also do justice to those facts of experience which, one believes, can only be explained with the help of a basic supposition that differs from the emission theory. Some people like to dismiss this point of view as a new fashion that was introduced by Poincaré, Duhem and others. In so doing they overlook entirely the fact that the same way of thinking characterised the period a hundred years ago, one that is akin to our period in many ways (Neurath 1983: 28).

To develop a theory for the prize using a different'original analogy' is in my view a very interesting case of underdetermination. In a more mathematicised form it appears in Wigner's famous 'The Unreasonableness of Mathematics in the Natural Sciences' paper. As opposed to traditional underdetermination of scientific theory by data (often likened to a curve-fitting problem), Gelfert argues that

Wigner's puzzle raises the spectre of underdetermination of scientific theory by (a multiplicity of conceivable) mathematical frameworks: If we had inherited a different set of mathematical concepts or frameworks, our scientific theories of the very same phenomena, though equally successful, might have looked vastly different (Gelfert 2014).

The discussed interpretations of the 'same' prism-experiments utilised different frameworks, Newton's physical theory competed first with the (atemporal) geometrical optical tradition and polar (two-colour) modificationist schemes, later with other physical theories (like wave theories in the wake of Huygens), and Goethe's developmental account of prism-colours. Neurath analysed a set of competing views, and it is easy to understand his plea for a 'multiplicity of reality'. His analysis also revealed that by data they were not underdetermined, because they differed as to how they select and neglect facts. His social epistemology was informed by the hint that with patience more than one of the alternatives could be improved to the level that the spectre of underdetemrination is raised.

About Newton, Neurath noted:

It was precisely his inconsistency that was highly stimulating and gave posterity an opportunity to form hypotheses of many kinds, many of which have proved fertile. According to his words he attaches little weight to the character of light, but in fact he is very dependent on the notions that he forms of it. Actually he expresses them several times (Neurath 1983: 20).

If Neurath is right about his evaluation (trying at various times to classify the theory), then Newton's optics is not necessarily the ideal theory to attempt to provide a'strong' rational reconstruction of. It is very difficult to reconstruct Newton's position, his New Theory only 


\begin{tabular}{|l|llll|}
\hline & Journal : Small 10838 & Dispatch : $\mathbf{5 - 1 - 2 0 1 8}$ & Pages : 17 \\
& Article No. : 9391 & $\square$ LE & $\square$ TYPESET \\
MS Code : JGPS-D-16-00074 & $\downarrow \mathrm{CP}$ & $\checkmark$ DISK \\
\hline
\end{tabular}

Theory-Containment in Controversies: Neurath and Müller on...

\section{Conclusion}

provided an idealised sketch of a theory, and, when challenged, he argued that it could be defended. (Laymon 1978). And this sketch could be interpreted various ways. To prove the fruitfulness of his insight, Newton worked for decades on extending the theory to other types of colours, other optical phenomena, to engulf even parts of chemistry. And some argue that it fit Boyle's chymical project from the start (Newman 2010), so a strong reconstruction of the 'limited' domain Müller tackles should not disregard that the New Theory was also a chemical achievement. It was an eminent example of separation and reintegration by the well-known adept of chymistry, even Lavoisier's table of elements started with light. To claim that "we don't exactly know what Newton's optical theory was", is probably easier to defend than any of the singular (propositional) reconstructions available. For Müller the task ahead is primarily to pass judgment, to decide on who is right and who is wrong, and not to do a historical study (\$I.1.12, p. 38). But one can only pass judgment, when the case is heard and understood.

Müller's aim is to confront Newton's Theory with an isomorphous object (p. 431). Given inverted conditions, the isomorphic mapping of the two experimental scenarios is used to develop inverted theories. If his inverted theory is a symmetrical anti-theory of a theory then the two are not that different (logically compatible and empirically equivalent, see Lampert 2017). Müller's approach, informed by Quine, ends up with equivalent theories that posit unobservables (p. 153), cannot be empirically ruled out, and are admittedly not very plausible given extrinsic criteria (p. 386). They are equally bad (p. 437).

Müller relies on some of the commonly used tools, but I remained unconvinced as to whether the orthodox apparatus without a clearly explicated methodology of reconstruction, like Vicker's theory-eliminativism (Vickers 2014) can provide a strong interpretation of the controversy or any of the positions. If some of Newton's inconsistencies had epistemic benefits, then it is questionable that the type of framework Müller picks is the best for the reconstructive enterprise. How could one find the isomorphous object, the antitheory, if there is reason to believe that the theory is not a sharply bounded object, it is blurred, vague, or simply fuzzy? ${ }^{14}$ I would argue that for the philosophy of experimentation, Neurath's treatment offers the richer perspective:

We must try to see clearly how a physical theory hinges on the images used, and how far on those features that actually carry the argument. Perhaps we cannot grasp some developments unless we consider the images and pictures; in other uses we must rely on what governs the mathematical treatment of phenomena; or, maybe, both ways of looking at it are steps (Neurath 1973: 102).

Müller displays his approach as a further elaboration of one of Goethe's critical insights into Newton's optics and claims: prismatic experiments can provide a case for Quine's underdetermination thesis. Müller's book is, perhaps inadvertedly, integrating HPS. This is a thought-provoking game, ending with an appraisal of Goethe's criticism of Newton's theory of Light, and re-opening the debate (p. 439). I clearly recognise his early warning that one cannot do rational reconstruction and true-to-details analysis in one book (p. 39). Nonetheless, the philosophical quest runs the risk of modifying the initial views,

${ }^{14}$ Using fuzzy sets was first developed for legal systems, but scientific controversies have the complexity that their analysis is also supported (Wroblewski 1983; Dascal 2003, pp. 333-335). 


\begin{tabular}{|l|llll|}
\hline & Journal : Small 10838 & Dispatch : $\mathbf{5 - 1 - 2 0 1 8}$ & Pages : 17 \\
& Article No. : 9391 & $\square$ LE & $\square$ TYPESET \\
& MS Code : JGPS-D-16-00074 & $\downarrow \mathrm{CP}$ & $\boldsymbol{V}$ DISK \\
\hline
\end{tabular}

G. Á. Zemplén

610 simplifying stakes, and distorting positions in attempts to tidy them up. Judgment can only 611 be based on evaluation, but the topic was and still is controversial. In the spirit of the dissoi 612 logoi, I represented a fundamentally different approach, one that does not assume the 613 theories in question to be static or clearly definable entities.

614 I take strong reconstructions to be attempts to provide charitable reconstructions of 615 scientist's arguments and claims, given any normative framework on evaluation, 616 acknowledging that there can be various analytical stances. Müller's local example for 617 underdetermination eliminates a whole lot of the proof-structures it works with (p. 371) 618 and assumes that the theories in question can be reduced to a few sentences pertaining to a 619 restricted domain, optics. Müller attempts to delimit the problem of underdetermination, 620 but if Neurath's perspective is more justified, then, as opposed to some other theories, this 621 simplification might not pertain to the optical/colour theories in question. When contexts are simplified to provide strong readings of theoretical content (without full explication), we often fail to see the embeddedness of the 'theory proper' in the complex proof structure incorporating evidence, visuals, neologisms and hedgings.

My general interest was in studying how a 'product-oriented' philosophical reconstructive practice can contain aspects of scientific controversies, 'processes', that gradually unfold and that -in this particular case - has lasted over three centuries. For both protagonists of the book, their early publications polarised opinions, their mature works gave rise to opposing camps. Their theories developed, responded to criticisms and incorporated 630 new data. Methodological notions had argumentative functions, and in the multi-party 631 disagreements complex escape trees are more apt ways of displaying the positions than assuming a bounded set of propositions. Looking at the historiography of the controversy, few theories appear less containable than Newton's and Goethe's theories of colour.

Acknowledgements The work was supported by the MTA Lendület Science and Morals Research Group and the "Integrative Argumentation Studies" NKFI-OTKA K 109456 Grant. I appreciate the helpful 636 comments by István Danka and two anonymous reviewers.

\section{References}

Amrine, F. (1990). The metamorphosis of the scientist. Goethe Yearbook, 5, 187-212.

Biddle, J. (2013). State of the field: Transient underdetermination and values in science. Studies In History and Philosophy of Science Part A, 44(1), 124-133.

Burwick, F. (1989). The new english edition of Goethe's works. Eighteenth-Century Studies, 23(1), 62-72.

Cohen, M. R., \& Drabkin, I. E. [1948 (1969)]. A source book in Greek science (Source Books in the History of Science). Cambridge, MA: Harvard University Press.

Dascal, M. (2003). Interpretation and understanding. Amsterdam: John Benjamins.

Dijksterhuis, F. J. (2004). Once snell breaks down: From geometrical to physical optics in the seventeenth century. Annals of Science, 61, 165-185.

Duck, M. J. (1987). The Bezold-Brücke phenomenon and Goethe's rejection of Newton's Opticks. American Journal of Physics, 55(9), 793-796.

Gelfert, A. (2014). Applicability, indispensability, and underdetermination: Puzzling over Wigner's 'unreasonable effectiveness of mathematics'. Science and Education, 23(5), 997-1009.

Goethe, J. W. V. (1988). Scientific studies (D. Miller, Trans., Vol. 12, Suhrkamp Edition in 12 Volumes). New York: Suhrkamp.

HA: Goethes Werke in 14 Bänden, Hamburger Ausgabe, 1953. Hamburg.

Halvorson, H. (2012). What scientific theories could not be. Philosophy of Science, 79(April), $183-206$.

Hegge, H. (1987). Theory of science in the light of Goethe's science of nature. In F. Amrine, F. J. Zucker, \& H. Wheeler (Eds.), Goethe and the sciences: A reappraisal (Vol. BSPS 97). Dordrecht: D. Reidel Pub. Co.

Holtsmark, T. (2012). Colour and image. Berlin: Logos. 


\begin{tabular}{|l|llll|}
\hline & Journal : Small 10838 & Dispatch : $\mathbf{5 - 1 - 2 0 1 8}$ & Pages : 17 \\
& Article No. : 9391 & $\square$ LE & $\square$ TYPESET \\
& MS Code : JGPS-D-16-00074 & $\downarrow$ CP & $\checkmark$ DISK \\
\hline
\end{tabular}

Theory-Containment in Controversies: Neurath and Müller on...

660

661

662

663

664

665

666

667

668

669

670

671

672

673

674

675

676

677

678

679

680

681

682

683

684

685

686

687

688

689

690

691

692

693

694

695

696

697

698

699

700

701

702

703

704

705

706

707

708

709

710

711

712

713

714

715

716

Kuhn, T. S. (1958). Newton's optical papers. In I. B. Cohen (Ed.), Isaac Newton's papers and letters on natural philosophy (pp. 27-45). Cambridge: Harvard University Press.

LA: Goethe, Die Schriften zur Naturwissenschaft. Weimar: Herausgegeben im Auftrage der Deutschen Akademie der Naturforscher (Leopoldina).

Lampert, T. (2017). Underdetermination and provability: A reply to Olaf Müller. British Journal for the History of Philosophy. https://doi.org/10.1080/09608788.2016.1255177.

Laymon, R. (1978). Idealization, explanation, and confirmation. PSA, I, 336-350.

Lohne, J. A. (1977). Nova experimenta crystalli islandici disdiaclastici. Centaurus, 21(2), 106-148.

Müller, B. (Ed.). (1989). Goethe's botanical writings. Connecticut: Ox Bow Press.

Müller, O. L. (2015). Goethe mit Newton im Streit um die Farben. Frankfurt am Main: S. Fisher.

Müller, O. L. (2016). Prismatic equivalence: A new case of underdetermination-Goethe vs. Newton on the prism experiments. British Journal for the History of Philosophy, 24(2), 322-346.

Neurath, O. (1914/5). Zur Klassifikation von Hypothesensystemen (Mit besonderer Berücksichtigung der Optik). Jahrbuch der Philosophischen Gesellschaft an der Universität zu Wien 1914 und 1915, 39-63.

Neurath, O. (1915). Prinzipielles zur Geschichte der Optik. Archiv für die Geschichte der Naturwissenschaften und der Technik, 5, 371-389.

Neurath, O. (1973). Empiricism and sociology. Dordrecht: D. Riedel.

Neurath, O. (1983). Philosophical papers, 1913-1946. Dordrecht: D. Riedel.

Newman, W. R. (2010). Newton's early optical theory and its debt to chymistry. In D. Jacquart \& M. Hochmann (Eds.), Lumière et vision dans les sciences et dans les arts, de l'Antiquité du XVIIe siècle. Geneve: Librairie Droz.

Newton, I. (1671-1672). New theory about light and colours. Philosophical Transactions, 80, 3075-3087.

Newton, I. (1952). Opticks or a Treatise of the Reflections, Refractions, Inflections \& Colours of Light. London: Dover Publications.

Newton, I. (1984). The optical papers of Isaac Newton (Vol. I). Cambridge: Cambridge University Press.

Palmer, S. E. (1998). Color, consciousness and the isomorphism constraint. Behavioural and Brain Sciences, 22, 923-989.

Ribe, N. M. (1985). Goethe's critique of Newton: A reconsideration. Studies in History and Philosophy of Science, 16(4), 315-335.

Ribe, N., \& Steinle, F. (2002). Exploratory experimentation: Goethe, land, and color theory. Physics Today, 57, 43-47.

Sepper, D. L. (1988). Goethe contra Newton: Polemics and the project for a new science of color. Cambridge: Cambridge University Press.

Shapiro, A. E. (1973). Kinematic optics: A study of the wave theory of light in the seventeenth century. Archive for History of Exact Sciences, 11, 134-266.

Shapiro, A. E. (1980). The evolving structure of Newton's theory of white light and colour. ISIS, 71(257), $211-235$.

Turnbull, H. W. (Ed.). (1959). The correspondence of Isaac Newton I. 1661-1675. Cambridge: Cambridge University Press.

Turnbull, H. W. (Ed.). (1960). The correspondence of Isaac Newton II. 1676-1687. Cambridge: Cambridge University Press.

Vickers, P. (2014). Scientific theory eliminativism. Erkenntnis, 79(1), 111-126.

Westphal, J. (1987). Colour: Some philosophical problems from Wittgenstein, Aristotelian Society Series. Oxford: Blackwell.

Wroblewski, J. (1983). Fuzziness of legal system. Essays in Legal Theory in Honour of Kaarle Makkonen, Oikeustiede-Junsprudentia XVI, pp. 315-319.

Young, T. A. (1814), Zur Farbenlehre. On the doctrine of colours. The Quarterly Review, 10, 427-441.

Zemplén, G. Á. (2006a). Auxiliary images: Appropriations of Goethe's theory of colours. In S. Zielinski, \& D. Link (Eds.), Yariantology 2: On deep time relations of arts, sciences and technologies (pp. 169-202). Köln: Verlag der Buchhandlung Walther König.

Zemplén, G. Á. (2006b). The development of the Neurath-principle: Unearthing the Romantic link. Studies in History and Philosophy of Science A, 37(4), 585-609.

Zemplén, G. Á. (2017a). Diagrammatic carriers \& the acceptance of Newton's optical theory. Synthese. https://doi.org/10.1007/s11229-017-1356-5

Zemplén, G. Á. (2017b). Structure and advancement in Goethe's morphology. In J. Faflak (Ed.), Marking time: Romanticism and evolution. Toronto: Toronto UP. 